(RESEARCH ARTICLE)

\title{
Microbiological quality of non-registered table water sold in Sokoto Metropolis Northwestern Nigeria
}

\author{
Kasarawa AB 1, Salau IA 2, * and Aliyu RM 3 \\ ${ }^{1}$ Department of Science Laboratory Technology, Umaru Ali Shinkafi Polytechnic, Sokoto. Nigeria \\ 2 Department of Biological Sciences, Federal University Gusau, Zamfara, Nigeria. \\ ${ }^{3}$ Department of Veterinary Microbiology, Usmanu Danfodiyo University, Sokoto, Nigeria
}

Publication history: Received on 09 April 2020; revised on 04 June 2020; accepted on 05 June 2020

Article DOI: https://doi.org/10.30574/wjarr.2020.6.3.0095

\begin{abstract}
Table drinking water, often called as 'Pure water' is generally accepted safe for consumption. The study was aimed at comparatively analyze for microbiological quality of non-registered table water sold in Sokoto Metropolis using microbial culture, microscopic and Biochemical identification. Eight (8) samples each were purchased from nonregistered factories within Sokoto Metropolis. Streak plate method was used for the isolation of bacteria on Nutrient agar (NA) medium and Sabouroud Dextrose Agar (SDA) medium for isolation of fungi. Incubation period at $37^{\circ} \mathrm{C}$ for 24 hours, for bacteria and $25^{\circ} \mathrm{C}$ for 72 hours for fungi was considered. All the samples yielded growth for bacteria while only 4 samples were positive to growth of fungi. The bacteria isolated from samples analyzed were species of Bacillus and Salmonella while fungal isolates recovered were Aspergillus and Penicillium species. The presence of these bacteria at high levels is a matter of serious concern as some of these organisms are causative agents of many disease of medical importance. It is therefore recommended that regulatory bodies should intensified efforts in the monitoring of nonregistered factories of table water and discourage the proliferations and consumption of unhygienic table water in the study area.
\end{abstract}

Keywords: Microorganisms; Table water; Bacteria; Fungi and Sokoto

\section{Introduction}

Safe and potable water supplies in urban centers in Nigeria are still inadequate in spite of over five decades of independence and several efforts from various governments. In many developing countries, availability of water has become a critical and urgent problem and it is a matter of great concern to families and communities depending on nonpublic water supply system [1]. Increase in human population has exerted an enormous pressure on the provision of safe drinking water in developing countries [2]. However, table water can be transferred to as ready to drink packed and machine- sealed water. This water is referred to as "pure water" by many of the locals in Nigeria and other African neighboring countries like Ghana, Togo etc. Table water is also sold in hand filled, hand-tied plastic bags. This is locally referred to as "ice water" [3].

Machine sealed Table water that is produced in industries is referred to as factory-produced, while that produced by manually filling plastic bags with water and knotting the water - filled bags is referred to as "hand- tied" Table water [4]. Safe and potable water supplies in urban centers in Nigeria are still inadequate in spite of over five decades of independence and several efforts from various governments. In many developing countries, availability of water has become a critical and urgent problem and it is a matter of great con cern to families and communities depending on non- public water supply system [1].Increase in human population has exerted an enormous pressure on the provision of safe drinking water in developing countries [2]. Towards the Millennium Development Goals- Action for water and Environmental Sanitation is timely in the light of the problem of poor availability and access to good drinking water in

\footnotetext{
* Corresponding author: Salau Ibrahim Alhaji
} 
many countries of the world including Nigeria. "About one-fifth of the world's population lack access to safe drinking water, and about half lack adequate sanitation. About 40 percent of the world's population lives in countries with moderate to high water stress. By 2025, this figure could rise to 50 percent. Yet, with the help of policy and legal reform, international cooperation community and private sector participation, technical innovation- there are encouraging signs that the crisis could be averted. The connectivity between poverty, hunger, availability, affordability and access to drinking water to sustainable development is succinctly described by the goals of the millennium declaration [4]. "The links between water, health, poverty are numerous and complex. Access to safe water affects adequate sanitation which in turn drives the risk of water borne diseases especially in poor urban communities. The urban poor often spend up to 10 -20 times more on water from vendors than piped water [4].

Furthermore, unsafe water is a global public health threat, placing persons at risk for a host of diarrheal and other diseases as well as chemical intoxication [5]. Unsanitary water has particularly devastating effects on young children in the developing world. Each year, more than 2 million persons, mostly children less than 5 years of age, die of diarrheal disease accounted for $17 \%$ of all death from 2000 to 2003 [6], ranking third among causes of death, after neonatal causes and acute respiratory infections. Nearly $90 \%$ of diarrheal related deaths have been attributed to unsafe or inadequate water supplies and sanitation [6] conditions affecting a large part of the world's population [5]. An estimated 1.1 billion persons (one sixth of the world's population) lack access to clean water and 2.6 billion to adequate sanitation $[5,6]$. The principal objectives of municipal water are the production and the production of safe water that is fits for human consumption $[1,7]$.

The guidelines for quality water are intended for use by countries as a basis for the development of national standards which if properly implemented will ensure the safety of drinking water [6]. The quality of drinking water has attracted great attention worldwide because of implied public health impacts. However, the information generated from this study will provide a baseline data for water production factory, table Water Company and ministry of health on the importance of hygienic practice in processing and packaging of water. The results obtained from this study will help the ministry of water resources to formulate guidelines for proper hygienic management and also provide opportunity for the chain actors and other stakeholders to determine appropriate mitigation measures at the various points.

This research is aimed to analyze the micro flora isolated from registered table water sold in Sokoto Metropolis.

\section{Material and methods}

\subsection{Study area}

Sokoto is the capital of Sokoto State, located in the extreme Northern West of Nigeria, near the confluence of the Sokoto River and the Rima River. With an annual average temperature of $28.3^{\circ} \mathrm{C}\left(82.9^{\circ} \mathrm{F}\right)$.Sokoto is on the whole, a very hot area, however maximum daytime temperature are for most of the year generally under $40^{\circ} \mathrm{C}\left(104.0^{\circ} \mathrm{F}\right)$. The rainy season is from June to October during which showers are a daily occurrence. It is characterized by 3-4 months annual rainfall (June- September) and 7-8 months dry season (October- May) [8].

\subsection{Study Design}

The samples each were randomly selected from each factory including Annest, Abbana, Jajo, Ilham, M- Safiya, Mugage and De-mimi table water. Samples were transported to the Microbiology Laboratory of Umaru Ali Shinkafi Polytechnic of Sokoto for microbiological analysis.

\subsection{Microbiological Analysis}

\subsubsection{Nutrient agar Preparation}

$7 \mathrm{~g}$ of nutrient agar was weighed and dissolved into $250 \mathrm{ml}$ of distilled water; the mixture was heated to dissolve. After dissolving, it was then autoclave at $121^{\circ} \mathrm{C}$ for 15 minutes; the prepared media was poured into petri-dishes and flamed. The mixtures were allowed overnight for sterility testing.

\subsubsection{Inoculation of the samples}

Samples collected were centrifuged and a loop of the filtrate was streak onto the plate of nutrient agar and PDA medium. The cultured plates were then incubated for 24 hours at $37^{\circ} \mathrm{C}$ for bacteria and 72 hours for fungi. Suspected bacterial and fungal colonies were observed and stained using grams staining and lacto phenol cotton blue staining techniques. 
Stained slides were mounted and microscopically view using high power objective. Suspected gram negative rods on microscopy were subculture onto their respective selective media and further identified using biochemical test.

\subsubsection{Biochemical test}

Catalase tests

This test demonstrates the presence of catalase, an enzyme that catalyse the release of oxygen from hydrogen peroxide. One drop of 3\% hydrogen peroxide solution was placed on a clean slide. A loop full from 24 hour culture was added. The release of bubbles (of oxygen) indicated the presence of catalase in the culture under test [9].

\section{Haemolysis test}

Blood agar was prepared by adding blood into the nutrient agar. The media was then transferred into petridish and allow to gel for some minutes. The inoculum was inoculated into the culture media and incubated for 18 to 24 hours. The culture media was observed for beta haemolysis. Further Imvic tests including indole, methylred, vogesproskaeur and citrate production tests were carried to characterize the negative rods.

\section{Results}

Similarly microscopic examinations of stained slides for fungi are compared with atlas of mycology and identified. Out of the 80 samples of table water, samples collected and analyzed for bacterial and fungal pathogens in this study, there was for bacteria. In the entire sample (100\%) while 4 samples showed growth for fungal pathogens (50\%). The bacterial pathogens isolated in the samples were Salmonella and Bacillus species, the fungal pathogens recovered were species of Aspergillus and Penicillium. The results are presented in Table 1 and 2.

Table 1 The Distribution of Bacteria Isolated From unregulated water samples in Sokoto Metropolis

\begin{tabular}{lll}
\hline Bacteria isolated & No of positive & Frequency of occurrence (\%) \\
\hline Salmonella spp & 10 & $12.5 \%$ \\
Bacillus spp & 70 & $87.5 \%$ \\
Total & 80 & $80(100 \%)$ \\
\hline
\end{tabular}

From the above, Bacillus spp showed higher frequency of occurrence of 70(87.5\%) and Salmonella spp were least in occurrence $10(12.5 \%)$.

Table 2 Distribution of Fungi isolated from unregulated water sold in Sokoto Metropolis

\begin{tabular}{lll}
\hline Fungal isolates $(\mathbf{n = ~ 8 0 )}$ & No of positive & Frequency of occurrence (\%) \\
\hline Aspergillus spp & 30 & $37.5 \%$ \\
Penicillium spp & 10 & $12.5 \%$ \\
Total & 40 & $50 \%$ \\
\hline
\end{tabular}

Table 2 showed 50\% frequency positive for fungi with higher frequency of occurrence of Aspergillus spp 30(37.5\%) and Penicillium spp were less prevalent 10(12.5\%) recorded from unregulated table water.

\section{Discussion}

The results obtained from this study showed that out of the 80 water samples collected and analyzed for bacterial and fungal pathogens, there was growth for bacteria (100\%) in all the entire samples analyzed while $40(50 \%)$ samples showed growth positive for fungal pathogens. The bacterial pathogens isolated in the samples were Bacillus spp and Salmonella spp. However, the fungal pathogens isolated were species of Aspergillus and Penicillium. 
This is in agreement with the findings of Ajayi et al. [10] who had reported high prevalence of coliforms bacteria (47.5\%) isolated from packaged drinking waters in Ibadan, Nigeria in which larger proportions of Table water were found to show positive coliforms count compared to bottled waters.

The result also in accordance with the finding of [11] in Ogbomoso, South-western, Nigeria, who reported that Table water, was contaminated with Pseudomonas spp, Enterobactericeae spp and species of Bacillus. Also in agreement in the report by NAFDAC [12] in Owerri Metropolis who showed that unregulated water contained Kleibsella spp and Pseudomonas spp. The finding of this study is also similar to the work of in Kebbi State, Nigeria, who emphasize that Table water contained Staphylococcus aureus and Escherichia coli and opined that regulation regulatory bodies should take serious measure to seal such factories that were involved in production of unsafe- unhygienic table water.

The presence of these pathogens in such water could account for the incidence of diarrhea, food poisoning and gastroenteritis especially, among populace of the study area. Also, the presence of this pathogens raise public health concerns that need to be addressed. The need for microbial assessment of water for production of drinks should also be emphasized to reduce possible contamination.

\section{Conclusion}

Evidently, the results obtained in this study showed that unregulated water sold in Sokoto Metropolis contained contaminants with pathogenic organisms such as Bacillus spp, Salmonella spp, Aspergillus and Penicillium spp and thus unsafe drinking. It is recommended that regular monitoring and supervision of packaged water factories should be intensified by NAFDAC and other regulatory bodies to checkmate the production of safe drinking and ensure appropriate measures are taken against default factories.

\section{Compliance with ethical standards}

\section{Acknowledgments}

The authors express sincere thanks to Department of Science Laboratory Technology, Umaru Ali Shinkafi Polytechnic, Sokoto, Nigeria for the facilities provided to carry out this research work.

\section{Disclosure of conflict of interest}

The authors declare that they have no competing interests.

\section{References}

[1] Okonko IO, Ogunjobi AA, Adejoye OD, Ogunnusi TA and Olasogba MC. (2008). Comparative studies and Microbial risk assessment of different water samples used for processing frozen sea-foods in Ijora-olopa, Lagos State, Nigeria. African journal of Biotechnology, 7(16), 2902-2907.

[2] Umeh CN, Okorie OI and GA Emesiani. (2005). "Towards the provision of safe drinking water: the bacteriological quality and safety of sachet water in Awka, Anambra State," in Proceedings of the 29th Annual Conference and Genral Meeting on Microbes as Agents of Sustainable Development, p. 22, Nigerian Society for Microbiology (NSM), Federal University of Agriculture, Abeokuta, Abeokuta, Nigeria.

[3] McGranahan G, Lewin S, Fransen T, Hunt C, Kjellén M, Pretty Jand Virgin I. (1999). Environmental change and human health. Stockholm: Stockholm Environment Institute.

[4] Akunyili DN. (2003). The role of pure water and bottled water manufacturers in Nigeria. In Towards the millennium development goals-Actions for water and environmental sanitation: Proceedings of the 29th WEDC International Conference, Abuja, Nigeria, 85-88.

[5] Hughes JM and Koplan JP. (2005). "Saving lives through global safe water" Emerging Infectious Diseases, 11(10), 1636-1637.

[6] WHO. (2008). Guidelines for Drinking-Water Quality: Recommendations, vol. 1 of Incorporating First and Second Addenda, World health organization, Geneva, Switzerland, 3rd edition.

[7] Igbeneghu OA and Lamikanra A. (2014). "The bacteriological quality of different brands of bottled water available to consumers in Ile-Ife, south-western Nigeria," BMC Research Notes, 7, 859. 
[8] NPC/FRN. (2007). Nigeria Population Commission, Federal Rep. of Nigeria. Special FGN Gazette, 23.

[9] Harrigan WF. (1998). Laboratory methods in food microbiology. Gulf professional publishing, 55.

[10] Ajayi BA and Lamidi YD. (2015). Formulation of Ceramic Water Filter Composition for the Treatment of Heavy Metals and Correction of Physiochemical Parameters in Household Water, 101.

[11] Ayodele OS and Ajayi AS. (2015). Water quality assessment of Otun and Ayetoro Area, Ekiti State, South western Nigeria," Advancement in Science and Technology Research, 2(1), 8-18.

[12] National Agency for Food Drug Administration and Control. (2009). Guidelines for registration of food and water manufactured in Nigeria NAFDAC/RR/005/00.

\section{How to cite this article}

Kasarawa AB, Salau IA and Aliyu RM. (2020). Microbiological quality of non-registered table water sold in Sokoto Metropolis Northwestern Nigeria. World Journal of Advanced Research and Reviews, 6(3), 07-11. 